\title{
Evaluation of Clearness Index of Sokoto Using Estimated Global Solar Radiation
}

\author{
Ndilemeni C. C. ${ }^{1}$ M Momoh ${ }^{1}$, and J.O. Akande ${ }^{1}$, \\ ${ }^{I}$ Department of Physics, Usmanu Danfodio University, Sokoto, Sokoto State, Nigeria
}

\begin{abstract}
The clearness index at a point in Sokoto $\left(13^{0} N^{l}, 5^{\circ} .15^{l} E\right)$ was evaluated from global solar radiation estimated from sunshine hour data collected from NIMET. The clearness index was compared with global solar radiation, the transparency of Sokoto sky was investigated and the monthly variation of clearness index was evaluated. The results show that Sokoto has a clear weather as the clearness index is more than $50 \%$ throughout the year. The month of December has the highest clearness index of $62.9 \%$ while the month of August has the least value clearness index of 50.8\%. The low value of clearness index in August may be attributed to heavy rainfall associated with the month
\end{abstract}

Keywords: global solar radiation, clearness index, sunshine hour.

\section{Introduction}

Global solar radiationchanges and climatic variation are the most of the world's environmental problems . The variation in climatic parameters like pressure, temperature, rainfall, humidity, wind, precipitation can abruptly change. Droughts and floods are extreme climate events that percentage-wise are likely to change more rapidly than the mean climate[1]. Because they are among the world's costliest natural disasters and affect a very large number of people each year [2] it is important to monitor them and understand and perhaps predict their variability through the studies of solar radiation .It becomes imperative that weather parameter like global solar radiation should be studied because of its application in so many facets of daily activities. Global solar radiation is important in studying of climatic changes and global warming because of it is an indication of anthropogenic activities [3]. Also it can be used in optimal design and to predict the system performance of a solar devices [4]Conventionally, pyranometeris used to measure global solar radiation . There are other methods that can be used to estimate global solar radiation such as using the. relationship between global solar radiation and sunshine hour [5]

In spite of the fact that Sokoto state is blessed with abundant hours of sunshine it sill suffers from epileptic power supply. It therefore becomes necessary to find the relationship between global solar radiation and sunshine hour with a view of assessing the potentiality of solar energy as an alternative major source of electrical power supply.

In this work sunshine hour is used to estimate global solar radiation and hence to determine the transparency of Sokoto sky, evaluate the monthly variation of clearance index and to compare the estimated global solar radiation with clearance index of Sokoto.

\section{Methodology}

Mean sunshine hour(n) and day length $(\mathrm{N})$ data obtained from Nigeria Meteorological Agency (NIMET) was used to calculate solar radiation. The data obtained covered the period of ten years (2001-2010) at a point in Sokoto

$\left(13^{\circ} .1^{\prime} \mathrm{N}, 5^{\circ} .15^{\prime} \mathrm{E}\right)$.

The agency maintained a network of synoptic station at various locations in Nigeria. This station collects various metrological data on continuous basis in accordance with the standard procedure specified by the World Meteorological Organization (WMO).

The value of the solar radiation was calculated based on Angstrom method of prediction. [6]

$\frac{\mathrm{H}_{\mathrm{m}}}{\mathrm{H}_{\mathrm{o}}}=\mathrm{a}+\mathrm{b} \frac{\mathrm{n}}{\mathrm{N}}$

Where

$\mathrm{H}_{\mathrm{M}}$ is a measure of monthly mean daily global solar radiation falling on horizontal surface at Sokoto; $\mathrm{H}_{\mathrm{o}}$ is the monthly mean daily extraterrestrial radiation falling on horizontal surface in the absence of atmosphere, $\mathrm{n}$ is the monthly mean value of observed sunshine hour; $\mathrm{N}$ is the monthly mean value of day length of a particular location, $\mathrm{a}=0.31$ and $\mathrm{b}=0.47$ are climatologically determined regression constant using the relationship given by [7] as

$$
\begin{aligned}
& \mathrm{a}=-0.110+0.235 \cos \Theta+0.323(\mathrm{n} / \mathrm{N}) \\
& \mathrm{b}=1.449-0.553 \cos \Theta-0.694(\mathrm{n} / \mathrm{N})
\end{aligned}
$$


where $n / N$ is called the percentage of possible sunshine hour.

In equation (1) the value of $\mathrm{H}_{\mathrm{O}}$ which is the monthly mean daily extraterrestrial radiation measured in $\mathrm{MJ} / \mathrm{m}^{2}$ is determined using $[8]$ as

$\left.\mathrm{H}_{\mathrm{O}}=\frac{24 \times 3600}{\pi} \mathrm{Gsc}\left(1+0.033 \cos \frac{360 \mathrm{n}}{365}\right)\left(\cos \phi \cos \partial \sin \mathrm{W}_{\mathrm{s}}+\quad \sin \phi \sin \partial\right)+2 \pi \mathrm{W}_{\mathrm{s} /} 360 \sin \phi \sin \partial\right)$

Where

$\mathrm{G}_{\mathrm{sc}}=$ Solar constant $=1367 \mathrm{~W} / \mathrm{m}^{2}$

$\mathrm{W}_{\mathrm{s}}=$ Sunset hour angle for the typical day $\mathrm{n}$ for each month in degrees.

$=\operatorname{Cos}^{-1}(-\tan \phi \tan \partial)$

$\phi=$ Latitude angle for the location in degrees

$\partial=$ declination angle for the month in degree.

$\partial=23.45 \sin [360 * 248+(\mathrm{j} / 365)]$

Where $\mathrm{j}$ is the day number of the year with January 1 st as 1 and December $31^{\text {st }}$ as 36 .

$\mathrm{K}_{\mathrm{T}}$ known as clearness index is defined as the ratio of the global solar radiation to extraterrestrial radiation

\section{Data Presentation}

The sunshine hour(n), day length(N), solar radiation $\left(\mathrm{H}_{\mathrm{m}}\right)$, extraterrestrial solar radiation $\left(\mathrm{H}_{\mathrm{o}}\right)$ clearnessindex for ten years for sokoto state is presented in table 1 .

Table 1.0 summary of sunshine solar radiation or ten years (2001-2010)

\begin{tabular}{|l|l|l|l|l|l|l|}
\hline Month & $\begin{array}{l}\mathrm{n} \quad(\text { Monthly } \\
\text { Mean } \\
\text { Sunshine } \\
\text { Hour) }\end{array}$ & $\begin{array}{l}\text { N(Monthly } \\
\text { Average Day } \\
\text { Length) }\end{array}$ & $\begin{array}{l}\mathrm{n} / \mathrm{N}(\text { Percentage } \\
\text { orPossible } \\
\text { Sunshine Hour) }\end{array}$ & $\begin{array}{l}\mathrm{H}_{\mathrm{o}} \\
\left(\mathrm{MJm}^{2} / \mathrm{d}\right)\end{array}$ & $\begin{array}{l}\mathrm{H}_{\mathrm{m}} \\
(\mathrm{MJm} / \mathrm{d})\end{array}$ & $\mathrm{K}_{\mathrm{t}}=\mathrm{Hm}^{2} / \mathrm{H}_{\mathrm{o}}$ \\
\hline January & 7.60 & 11.40 & 0.676 & 29.434 & 17.873 & 0.595 \\
\hline February & 8.23 & 11.72 & 0.674 & 31.984 & 19.418 & 0.593 \\
\hline March & 7.91 & 12.02 & 0.626 & 34.656 & 20.390 & 0.575 \\
\hline April & 7.82 & 12.42 & 0.602 & 36.394 & 20.975 & 0.562 \\
\hline May & 7.74 & 12.71 & 0.574 & 37.068 & 21.017 & 0.554 \\
\hline June & 7.94 & 12.90 & 0.582 & 37.051 & 21.134 & 0.557 \\
\hline July & 6.74 & 12.79 & 0.530 & 36.971 & 20.200 & 0.533 \\
\hline August & 6.28 & 12.59 & 0.473 & 36.630 & 19.121 & 0.508 \\
\hline September & 7.27 & 12.28 & 0.592 & 35.291 & 20.250 & 0.559 \\
\hline October & 8.72 & 11.89 & 0.699 & 32.804 & 20.338 & 0.606 \\
\hline November & 9.10 & 11.59 & 0.748 & 30.086 & 19.294 & 0.627 \\
\hline December & 9.01 & 11.40 & 0.749 & 28.702 & 18.404 & 0.629 \\
\hline
\end{tabular}

\section{Results And Discussion}

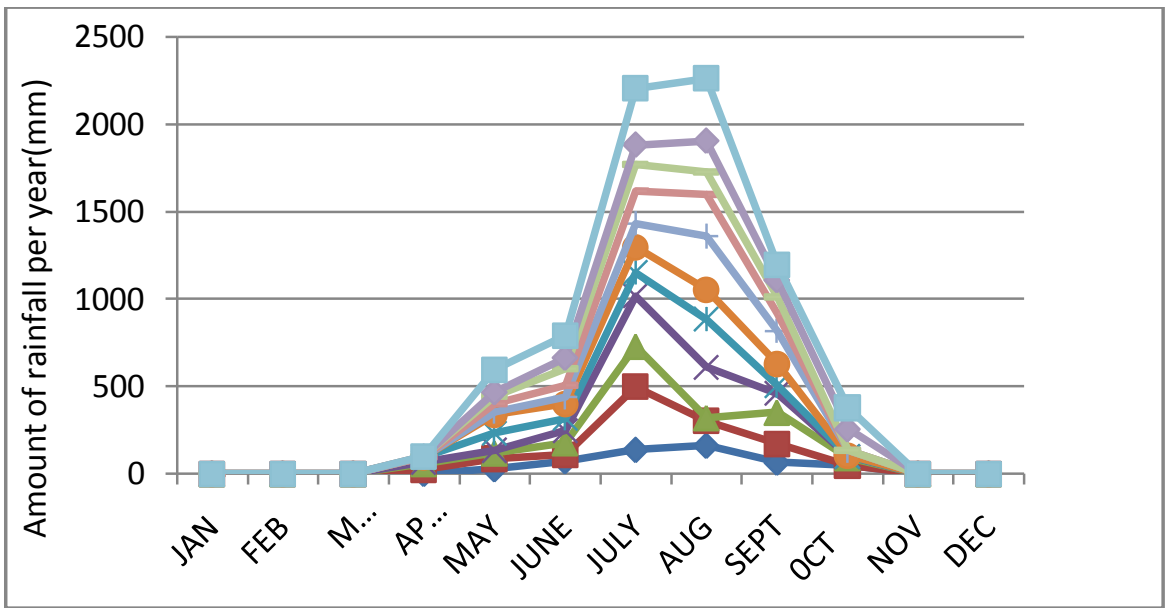

Fig 1.0.Monthly variation of rainfall with years. 


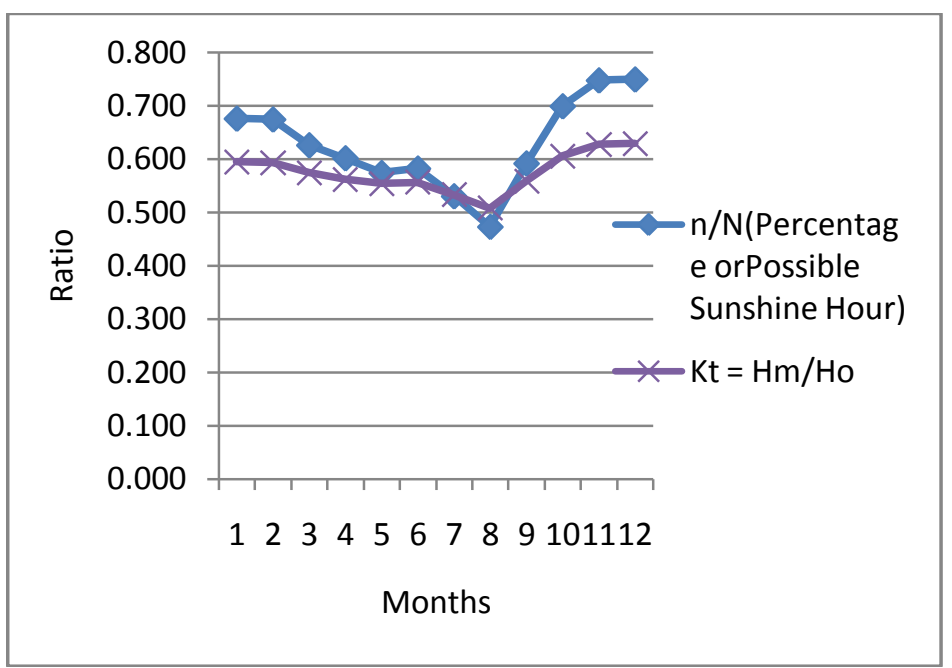

Fig 2.0. Percentage sunshine hour $(\mathrm{n} / \mathrm{N})$ and the clearness index

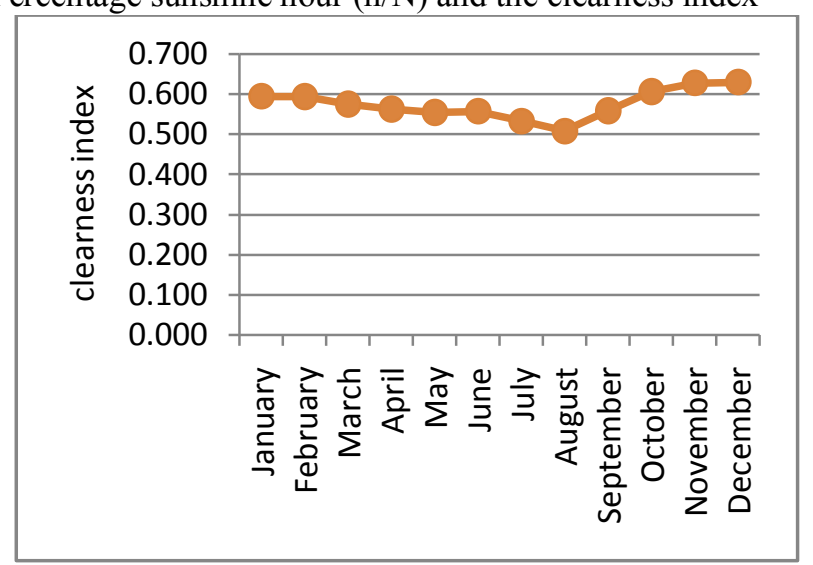

Fig 3.0 Monthly variation of the clearness index.

\section{Transparency of the Sky in Sokoto}

The transparency of the sky is indicated by the fraction of extraterrestrial radiation that reaches the surface as a global solar radiation. It is a measure of degree of the clearness of the sky, which is usually given by, $\mathrm{K}_{\mathrm{T}}=\mathrm{H}_{\mathrm{m}} / \mathrm{H}_{0}, \mathrm{H}_{\mathrm{m}}$ is the global solar radiation and $\mathrm{H}_{\mathrm{o}}$ is the extraterrestrial radiation. As seen in Table 1 and Fig. 2, clearness index has a value greater than fifty percent throughout the year which is very encouraging; thus indicating transparent sky throughout the year. In August however, the $\mathrm{k}_{\mathrm{T}}$ value is $50.8 \%$. This is not unexpected as it can be attributed to heavy rainfall as shown in Fig 1.0.

The sum of the regression coefficients $(a+b)$ is the transmissivity of the atmosphere for global solar radiation under perfectly clear sky conditions [9]. Similarly the intercept "a" is interpreted as the transmissivity of an overcast atmosphere [10]. The regression constants $(0.31,0.47)$ for Sokoto , is in conformity with the value of $0.6-0.7$ and $(0.3,0.4)$ reported for the tropics [11].

In general the clear sky transmissivity of most tropical regions seems to lie between $0.68-0.75$ ([4][11][12] )as the value is 0.78 .Though there is a variance of 0.03 . This could be as a result of the variations of solar activity which has taken place over the years. For instance[13] maintained that Solar Constant $\mathrm{I}_{\mathrm{o}}$ varies within a period of 11.2 years by about $1 \mathrm{~W} / \mathrm{m}^{2}$. This is caused by cyclical variations of solar activity.

\section{Comparing Clearness Index and Global Solar Radiation}

The highest range of monthly mean global solar radiation was between May and June, with June as the peak with mean monthly global solar radiation of $21.029 \mathrm{MJm}^{2} \mathrm{~d}$. The highest range of the clearness index is seen from October to February, with the peak in December which has the clearness index of 0.624, August has the least cleanness index of 0.503 , followed by July which is 0.530 . Fig 1 shows that the peak of the rainfall interchanges between the month of July and August. It therefore means that the heavy rainfall made the cloud muddy.

The implication of having clearness index greater than fifty percent is that the cloud is generally bright throughout the year, which shows that there is high potential of utilizing solar power in Sokoto state. Fig 3.0above shows monthly variation of the clearness index, and it has the least value in August.Fig. 4.0 also shows 
that the global solar radiation has the least value in the month of August which can be attributed to the same reason stated above.

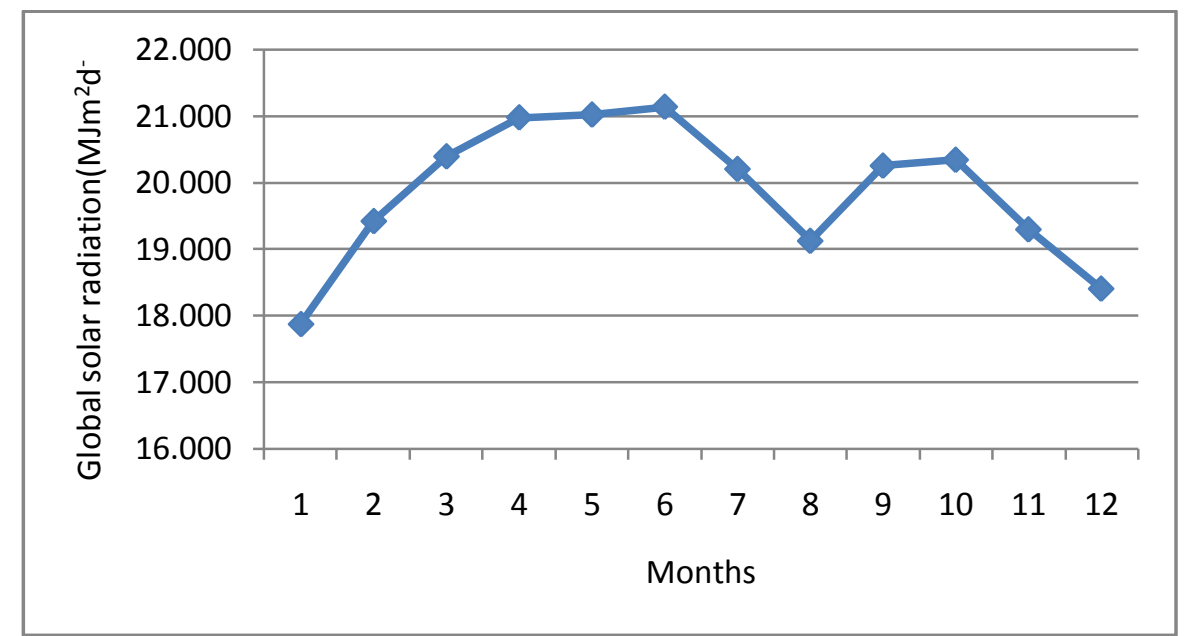

Fig 4.0 Comparing global solar radiation with months of the year

\section{Conclusion}

Evaluation of clearness index of Sokoto using estimated global solar radiation has lead to the following conclusions:

(1). The clearness index was found to be more than $50 \%$ in all the months of the year showing that Sokoto state has clear weather throughout the year which encourages solar energy utilizationthroughout the year .

Investors on solar energy can seize theopportunity and invest in solar electricity supply in Sokoto state.

(2) The monthly variation of clearness index revealed that the month of August has the least value of $50.8 \%$ and the month of December has the highest clearness index of $62.9 \%$

(3) Comparing clearness index and global solar radiation shows that the highest range of monthly mean global solar radiation was betweenthe month of may and June, with June as the peak with mean monthly global solar radiation of $21.13 \mathrm{MJm}^{2} / \mathrm{d}$. The highest range of the clearness index is seen from October to February, with the peak in December which has the clearness index of $62.8 \%$.The month of August has the least cleanness index of $50.8 \%$, followed by July which is $53.0 \%$.

\section{References}

[1] Trenbart (2003), K.E. Dai, R.. Rasmussen and M. Parsons D. B. The changingcharacter of precipitation. Bull. Amer. Meteor. Soc., 841205-1217.

[2] Wilhite,D.A. (2000)Drought as a natural hazard: Concepts and definitions. Droughts: A Global Assessment, Ed., Routledge, 3-18.

[3] Ramanathan V, CrutzePJ,Kiehi JT, Aerosols, Climate and the hydrological cycle, science (2001), 294; 2111-2124

[4] Ibrahim SMA Predicted and the measured global radiation in Egypt. Solar Energy, 35(2)(1985);185- 188

[5] Ying Wang and Lei ZhangRelationship between global solar radiation and sunshine duration for Northwest China.International Journal of the Physical Sciences (2010) Vol. 5(7), pp.1023-

[6] AngstromA. Solar and terrestrial radiation Q.J.R Met. Soc..(1924)50:121-126

[7] Tiwari, G.N. and Suleja, Sangeeta. Solar Thermal Engineering System, NarosaPublishing House, New Dehli, India (1997).

[8] Falayi ,E.O and Rabiu A.B “ Modelling of Global Solar Radiation using Sunshine duration Data” Nig. J physics 17(2005):181-186

[9] Revfein, K.J.A. “An Interpretation of the Coefficients of theAngstrom Equation”.Solar Energy (1983)31: 415.

[10] Augustine .C. and Nnabuchi .M.N. Correlation between global radiation in Warri.Pacific journal of science and Technology.(2009) 10(2):574-579

[11] Turton. S. M. A The relationship between total irradiation and sunshine in humid tropics solar energy.38 (1989.):353-354

[12] Sambo, A.S. "Empirical Models for the Correlation of Global Solar Radiation with Meteorological Data for Northern Nigeria". Solar and Wind Technology. 3(1986):89-93.

[13] Griffin Salima1 Geoffrey M. S. Chavula2. Determining Angstrom Constants for Estimating Solar Radiation in Malawi. International Journal of Geosciences, 3,(2012) 391-397. 